\title{
Users' perspectives on tour-guide training courses using 3D tourist sites
}

\author{
Yu-Fen Chen, Chihlee Institute of Technology, Taiwan \\ Huai-en Mo, National Taiwan Normal University, Taiwan
}

\begin{abstract}
Taiwan is currently attempting to develop itself into a twenty-first century tourist hub to take advantage of today's thriving global tourism economy. In the coming years, Taiwan anticipates an urgent demand for tour guides, and there is a clear need for training solutions that can serve a rapidly growing population. Computer-mediated virtual 3D situated tourist sites (3D-STS) may provide an efficient solution. This study investigates users' perspectives on a specially developed tour-guide training course employing 3D-STS technology. After participants completed the course, their responses to a survey questionnaire and follow-up interviews were compiled for statistical analysis. The results indicated that the overall experience of 3D-STS was satisfactory for trainees and showed a significant difference in the perspectives on 3D-STS of male and female trainees. However, one essential limitation of the study, that is, insufficient familiarity with the multiple advanced technologies, must be acknowledged. This could be a major obstacle for some users, interfering with their ability to access and process e-learning content. For more effective training outcomes for tour guides, the dynamic nature of 3D-STS as well as the characteristics of course content for tour guides should be considered carefully.
\end{abstract}

\section{Introduction}

Since the 1990s, tourism has been one of the world's largest and most thriving industries (Hall, 2006). By the early twenty-first century, the fast-growing international tourism industry generated half a trillion dollars in annual revenues, accounting for almost $10 \%$ of total international trade and almost half of the world's total trade in services (Eilat \& Einav, 2004). In today's economically favourable environment, Taiwan is attempting to position itself as a major tourist hub, promoting its travel destinations, cultural attractions and health services and facilities. A series of international marketing campaigns since 2004 has led to a marked increase in visitors to Taiwan. According to the World Economic Forum's 2008 Tourism and Travel Competitiveness Report (Blanke \& Chiesa, 2008), Taiwan's total inbound travellers made it the 43rd most popular travel destination among the 133 countries surveyed, and the seventh most popular in Asia, behind Singapore, Hong Kong, Japan, South Korea, Malaysia, and Thailand. In keeping with these statistics, as of June 2009, Taiwan boasted over 2,000 travel agencies and 34,000 employees (MOEA, 2009). The Taiwanese government even permitted the entry of tourists from mainland China in 2011.

As Brohman (1996) indicated, the appropriateness of tourism strategies are best measured according to the changing conditions and interests of each host community; and tourism-led development should conform to the long-term interests of the popular majority rather than the short-term goals of an elite minority. Strategies for handling the rapid expansion of tourism will necessarily vary throughout the world, but destination countries will almost universally face the same challenge that Taiwan now seeks to address: an urgent and growing demand for tour guides.

Tour-guide training courses have traditionally focused on transmitting to trainees a well-structured knowledge set that is delivered through instructors' lectures and explanations. Courses like these do not present trainees with exposure to target tourists and sites, nor do they offer opportunities for them to apply new understandings to authentic communication with tourists. Indeed, training that separates trainees from real-life tourist environments may preclude meaningful learning experiences and limit trainees' knowledge construction (Lee, Lee, \& Kim, 2004). To overcome these significant limitations, it has become necessary to integrate appropriate technologies and instructional strategies into the field of tourism training. 
Situated learning theory emphasizes meaningful knowledge construction within simultaneous situated contexts (McLellan, 1996). Learning occurs through sociocognitive conflicts among learners, and activities in authentic contexts trigger meaningful learning experiences. In other words, learning involves both situational and social attributes because the events of learning occur under the heavy influence of the context; similarly, contexts are a core requirement for learners to be able to relate knowledge to specific situations and solve authentic problems. Computer-aided e-learning in particular offers some intriguing possibilities for establishing effective and innovative contexts for situated or context-aware learning - for example, sensors may be used to capture elements of a user's environment and context, such as physical location, environmental parameters, and body temperature, and use these data points as input parameters for building up a personalized situation to support learning (Lau, Yen, Li \& Wah, 2013).

Advances like these illustrate how the development of computer-related technologies has enabled great improvements in learning object design through greater integration of instructional design, learning theory, and technology methodologies (Dede, 2009). The introduction of the Internet and 3D technologies in employee training fields has increased dramatically in recent years (Lee, Kim, Lee, \& Liu, 2005), and Bonk (2002) found that the second-most popular use of online training concerned job-related skill development. In keeping with this general trend, an increasing number of tourism practitioners have begun to take note of the usefulness of 3D online learning environments as either main or supplemental training delivery modes. Such tools can be of particular use for tour guides in training, who may not be able to personally visit tourist attractions in the course of their studies. Virtual platforms like Second Life offer a host of opportunities for training and development, and this study takes an important step toward measuring the potential value of these resources for tour guides in training.

Yet even as the possibilities of information technology (IT) have transformed the landscape of education and training, there remain certain asymmetries in social attitudes and IT usage. The issue of the gender gap in IT has been a theme in research throughout the past decade and beyond (Shashaani \& Khalili, 2001; Margolis \& Fisher, 2002; Broos, 2005; Wong \& Hanafi, 2007; Moghaddam, 2010), and some scholars have reasoned that men and women's differing patterns of IT usage are reflections of social constructions of gender and gender roles (Jackson, Eye, Fitzgerald, Zhao \& Witt, 2010). The extent to which the gender gap applies to computer-aided 3D situated tourist sites (3D-STS) training is an issue worthy of further exploration, especially as both men and women respond to the growing demand for well-trained tour guides.

The study reports on the results of a 3D-STS training course that used specially designed virtual tourist sites on Second Life. Findings are based on the reports of 100 volunteers, who participated in the computer-mediated course and completed follow-up surveys and interviews. Two central questions are addressed: First, what are users' perceptions of virtual 3D-STS? Second, is there a significant difference in the perspectives on $3 \mathrm{D}-\mathrm{STS}$ of male and female trainees?

\section{Literature review}

McLellan (1996) indicated that knowledge is separate from, but embedded within, experience, and is crucially interpreted by the learner. In other words, knowledge is about the interpretation of an environment. A key aspect of situated learning is that learning occurs in real situations and that knowledge is constructed through the continuous interaction between humans and situations (McLellan, 1996). This type of learning allows an individual to learn by socialization, visualization, and imitation. The ideal way to practice situated learning in tour-guide training, of course, is to take trainees to real workplaces, including domestic and overseas tourist sites. However, practitioners with limited training funds may not find this possible. Instead, these trainees can draw on virtual tools such as the 3D, Avatar, and online technologies of Second Life, which provide an appropriate platform to help create authentic learning experiences.

Indeed, computer technology can provide an environment in which learning can be fostered and supported. Recent developments in computer technology have facilitated complex human-machine interaction as well as the development of multimedia products. Computer hypermedia and networking technology can be used to create effective simulations of situations that cannot otherwise be experienced in a traditional classroom (McLellan, 1996). If learning activities can connect a real situation to an 
underlying theory, learning will seem realistic to learners (Downing, Moore, \& Brown, 2005). Thus, if computer multimedia can simulate realistic situations in a meaningful way, it can help learners to immerse themselves in those situations and to feel that they are gaining a form of real-life experience. It is essential, however, that virtual approximations accurately represent real-life situations. Although several previous studies (e.g. Herrington \& Oliver, 2000; Lee, Kim, Lee \& Liu, 2005) have suggested key situated learning principles for designing online environments, most of the content and processes in training courses do not start from real-life situations. These courses thus risk turning out trainees who cannot apply their learning to problem solving in real life or in work-related situations.

Smith (2008) proposes four basic requirements for an effective online course: (1) maintaining visibility, (2) providing feedback, (3) providing high-quality materials, and (4) removing obstacles to the extension of the learners' retention. Zielinski (2000) also proposed three components for course delivery: technology, course design, and learning environment. With the help of the Internet, wireless, and mobile technologies (Lau et al., 2013), trainees are able to work with more up-to-date and authentic information than the material in textbooks. Online resources can help trainees make connections between their training courses and the concerns of people in the real world. In these ways, new technologies can increase the generativity of course contents (Wiske, 2000; Lau et al, 2013).

In today's world, people use a wide assortment of multimedia tools as their primary form of communication. Thus, computer-mediated or online classes are becoming increasingly popular among modern learners (Muirhead \& Betz, 2002). Administrators are looking for ways to present information to trainees that will not only spark their interest but also encourage them to explore a subject thoroughly. Alongside these developments, social learning theory emphasizes the value of dialogue and collaboration in helping trainees to develop and articulate their understanding. Meaningful exploration usually means deeper understanding, which translates into higher task performance.

Advanced 3D imaging techniques emerged about two decades ago, originating in role-playing games, computer games, text-based multi-user virtual environments, and desktop virtual reality (Jones, Morales, \& Knezek, 2005). Today's 3D modelling images can graphically simplify complicated concepts and convey complex interrelationships that are difficult to visualize. Concepts and ideas that cannot easily be represented in words or even through illustrations can be easily created and viewed from different angles. These features have popularized the use of 3D technologies such as Active Worlds, Second Life, and River City for educational purposes (Qian, 2008). Many virtual education projects have had positive effects on learning effectiveness, such as the MARVIN project for New Zealand intermediate schools (Falloon, 2010), the use of Second Life in a human resource development course (evaluated by Broadribb and Carter [2009] using a quasi-experimental design), and a Midwestern university's application of Active Worlds to a science education training program (Omale, Hung, Luetkehans \& Cooke-Plagwitz, 2009). So far, 3D animation learning programs have mainly been developed and applied in academic environments, but the practical potential of the technology in everyday spaces such as the workplace remain largely unexplored.

As IT becomes more ubiquitous in our everyday lives, the lingering question of the extent of a gender gap in IT usage remains a theme in the literature (Margolis \& Fisher, 2002; Wong \& Hanafi, 2007; Jackson et al., 2010; Moghaddam, 2010). Studies undertaken over 20 years ago suggested that gender had a mediating effect on perceptions towards IT (Moghaddam, 2010), but it is important to note that IT at that time applied mainly to computers used for mathematical and word processing tasks. Today, the scope of IT is vast by comparison, as computers and personalized technologies are being used in various facets of life (Mitra et al., 2000; Lau et al., 2013). Hence, though extensive research on gender and IT has been carried out over the years, past findings may be irrelevant today because of the ever-expanding nature of IT. This study aims to revisit the core question, asking specifically whether male and female users have significantly different perspectives on 3D-STS e-learning technologies.

\section{Materials and methods}

\section{Participants}

The participants in this study were 100 new Taiwanese tour guides (40 males and 60 females) from five well-known travel agencies in Taiwan that together employ more than 4,200 workers. The researchers 
contacted the managers of these travel agencies, briefly explained the purposes of the study, and asked for voluntary participants. All participants were currently working as tour guides and had spent less than six months in the travel business. All submitted consent forms prior to participation.

\section{Instruments}

In addition to the training courses with 3D-STS, a questionnaire and a follow-up interview were conducted to collect data on trainees' perspectives on the training courses. A team of experts validated the instruments used in this study. The characteristics of each instrument are as follows.

$3 D-S T S$

Situated learning has eight key components (McLellan, 1996): stories, reflection, cognitive apprenticeship, collaboration, coaching, multiple practices, articulation of learning skills, and technology. Six of these were included in the design of 3D-STS, leaving out only cognitive apprenticeship and articulation of learning skills. The training course's learning activities were designed around the following elements: story-based animation to display situations; subject-integrated themes to integrate information about the basic necessities of travel (food, clothing, lodging, and transportation); social interaction with virtual tourists; and implicit hints to scaffold trainee learning. To mirror the local Taiwanese context, in which many tourists hail from mainland China, the animation design displayed realistic situations in a story-based trip to Sun Moon Lake, a first choice for tourists from mainland China. The course's story also included questions frequently asked by mainland Chinese tourists. Animated tutorials were created in order to coach trainees and deepen their schematic impressions of the learning concepts: in the tutorials, the computer program provided only guiding feedback, not correct answers, and trainees were exposed to analytical and problem-based questions requiring them to synthesize, analyse, and apply data or information shown in 3D-STS.

Research has shown that the greater spatial flexibility afforded by moving from 2D to 3D user interfaces further enhances user performance (Cockburn \& McKenzie, 2002). We applied 3D, Avatar, and online technologies from Second Life to construct training courses and learning tools. The 3D-STS learning tools consisted of an electronic notebook, a discussion board, and an electronic map (see sample image in Figure 1 below).

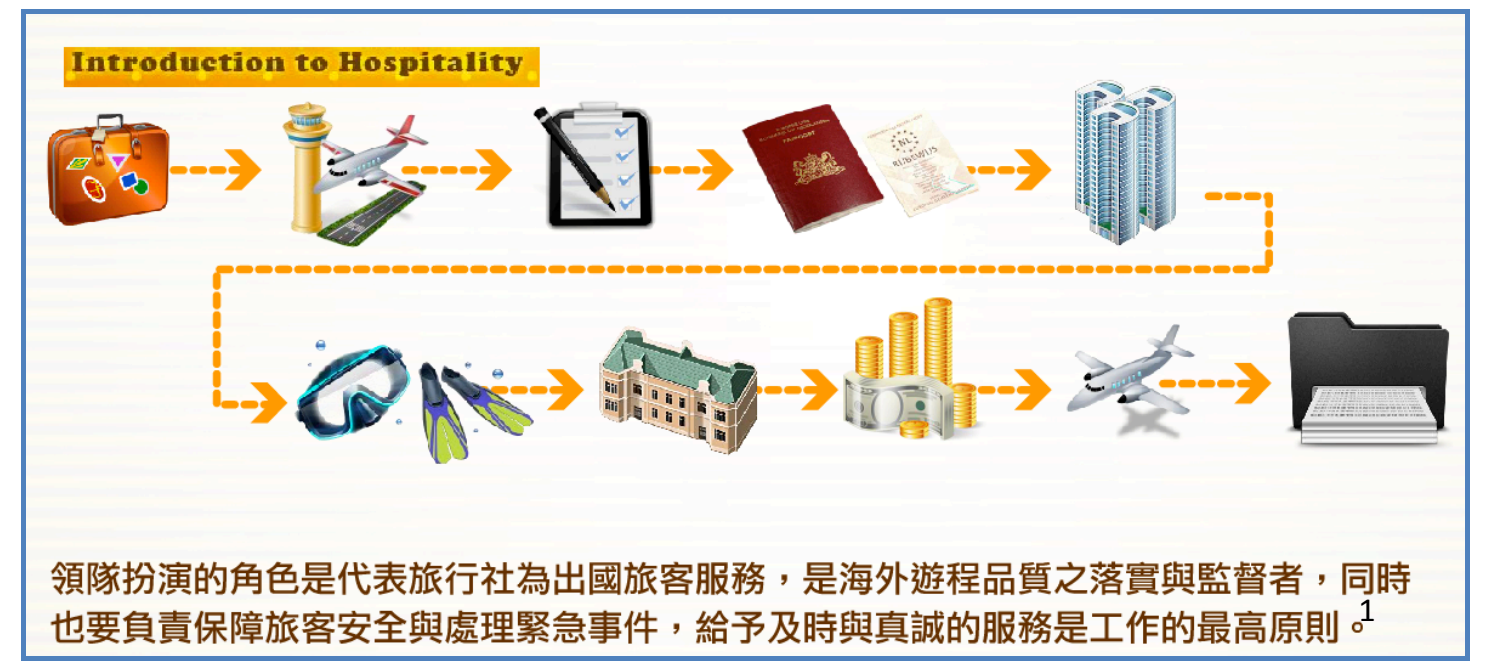

Figure 1. A Sample Image for the 'Introduction to Hospitality' Course

Translation of the text: 'The tour guides' offer a sort of tourist service, which is offered on behalf of travel agents. They supervise the tour and maintain its quality and are also responsible for ensuring tourist safety and handling emergencies. Finally, giving timely and sincere service is a matter of supreme principle for them'. 
The mapping of the components of 3D-STS is summarised below in Table 1.

Table 1

Mapping the Components of $3 D$-STS

\begin{tabular}{ll}
\hline Components & Mapping design of 3D-STS \\
\hline $\begin{array}{l}\text { Story-based animations } \\
\text { (3D tourist sites) }\end{array}$ & $\begin{array}{l}\text { The animation design displays realistic situations in a story-based } \\
\text { trip to Sun Moon Lake, a favourite tourist site in the middle of } \\
\text { Taiwan. }\end{array}$ \\
$\begin{array}{l}\text { Multiple practices \& } \\
\text { coaching } \\
\text { (Animated tutorials) }\end{array}$ & $\begin{array}{l}\text { Animated tutorials are designed to coach trainees' schema of } \\
\text { learning concepts. The formative tests that follow each unit in the } \\
\text { story provide trainees with multiple opportunities for practice. }\end{array}$ \\
$\begin{array}{l}\text { Self-reflection } \\
\text { (Electronic notebook) }\end{array}$ & $\begin{array}{l}\text { The electronic notebook was designed as a learning tool to help } \\
\text { trainees reflect on their experience and take notes on what they are } \\
\text { learning. }\end{array}$ \\
$\begin{array}{l}\text { Collaboration } \\
\text { (Discussion board) }\end{array}$ & $\begin{array}{l}\text { The asynchronous and synchronous online discussions provide } \\
\text { trainees with an opportunity to form virtual learning communities } \\
\text { for the purpose of collaborative learning. }\end{array}$ \\
\hline $\begin{array}{l}\text { Articulation of learning } \\
\text { technology }\end{array}$ & $\begin{array}{l}\text { The application of 3D, Avatar, and online technologies in Second } \\
\text { Life helps to display learning materials to trainees authentically and } \\
\text { immediately. }\end{array}$
\end{tabular}

Questionnaire

A questionnaire with 12 five-point Likert-type items was used to investigate trainees' perspectives on 3D-STS, ranging from 1 (strongly disagree) to 5 (strongly agree). The four dimensions of the questionnaire were interface and situation, tools and function, communication mechanism, and overall satisfaction of 3D-STS. The team of experts mentioned above was asked to validate the questionnaire items to ensure content validity.

\section{Follow-up interviews}

Semi-structured interviews with five open-end questions were conducted to investigate trainee understanding of the relative concepts in the course and to collect their opinions about 3D-STS. Twenty participating trainees ( 7 males and 13 females) volunteered to be interviewed. Each trainee was interviewed individually for 20 to 30 minutes.

\section{Procedure}

Before commencing the 3D-STS training courses, all trainees participated in a training session that included watching an online video for 30 minutes, which was an essential component in equipping trainees with basic skills to facilitate 3D-STS. Then, the trainees were asked to complete the 3D-STS program in two to three hours. The week after the training courses, a questionnaire was administered online. Results from the survey were analysed using ANOVA to test the study's hypotheses. Finally, 20 trainees volunteered to participate in one-on-one follow-up interviews a few weeks later, allowing time for the researchers to analyse the data and identify themes to target during the interviews. 


\section{Results and discussion}

Descriptive statistics (Table 2) were compiled for the analysis of each item in the questionnaire. Then, the collected data was analysed using Statistical Package for Social Science, version 18.0 (SPSS). The assumptions of normal distribution and homogeneity of variance for dependent variables were tested before applying the statistical methods, t-tests, and ANOVA (Stevens, 2002).

Table 2

Descriptive Statistics

\begin{tabular}{llll}
\hline & Mean & S.D. & t Value \\
\hline Male $(\mathrm{N}=40)$ & 16.50 & 2.55 & $1.94^{*}$ \\
Female $(\mathrm{N}=60)$ & 17.55 & 2.79 & \\
\hline
\end{tabular}

${ }^{*} \mathrm{p}<0.05$

The Kaiser-Meyer-Olkin value $(0.841>0.80)$ and the significance of Bartlett's test of Sphericity $(0.000<0.05)$ of the questionnaire revealed that its data are suitable for factor analysis. An exploratory factor analysis was undertaken using SPSS 18.0, and the internal reliability of each factor was assessed using Cronbach's $\alpha$. The results of factor analysis using the varimax rotation method showed that the 3D-STS questionnaire items were loaded on four factors (interface and situation, tools and function, communication mechanism, and overall satisfaction). The percentage of cumulative variance is $63.841 \%$. The level of internal reliability of items within each dimension was acceptable, with Cronbach's $\alpha$ ranging from 0.71 to 0.81 , as shown in Table 3 .

The four dimensions of the 3D-STS questionnaire had scores higher than 4.00 (Table 3), indicating that the overall experience of 3D-STS was satisfactory for trainees. The score on the dimension of interface and situation was the highest, at 4.45. This implies that most trainees were satisfied with the special interface and the 3D-STS built with Second Life. The score on overall satisfaction was 4.37, followed by tools and function (4.20) and communication mechanism (4.11). 
Table 3 Summary of Factor Analysis on the 3D-STS Questionnaire

\begin{tabular}{|c|c|c|c|c|}
\hline $\begin{array}{ll}\text { Items } & \text { Dimensions } \\
\end{array}$ & $\begin{array}{l}\text { Interface } \\
\text { and } \\
\text { situation }\end{array}$ & $\begin{array}{l}\text { Tools and } \\
\text { function }\end{array}$ & $\begin{array}{l}\text { Communication } \\
\text { mechanism }\end{array}$ & $\begin{array}{c}\text { Overall } \\
\text { satisfaction }\end{array}$ \\
\hline $\begin{array}{l}\text { The interface of 3D-STS helped me feel I } \\
\text { was in an authentic situation. }\end{array}$ & .801 & & & \\
\hline $\begin{array}{l}\text { The interface layout of 3D-STS is easy to } \\
\text { understand. }\end{array}$ & .778 & & & \\
\hline $\begin{array}{l}\text { Being able to play as an Avatar in 3D-STS } \\
\text { makes me feel that the learning situation is } \\
\text { close to real life. }\end{array}$ & .705 & & & \\
\hline $\begin{array}{l}\text { 3D-STS provided me with appropriate tools } \\
\text { for learning. }\end{array}$ & & .510 & & \\
\hline $\begin{array}{l}\text { 3D-STS provided me with necessary } \\
\text { functions for learning. }\end{array}$ & & .833 & & \\
\hline $\begin{array}{l}\text { The tools and functions in 3D-STS operate } \\
\text { smoothly only if the Internet is available. }\end{array}$ & & .708 & & \\
\hline $\begin{array}{l}\text { Online dialogue and discussions with peers } \\
\text { improved my understanding of the program } \\
\text { content. }\end{array}$ & & & .710 & \\
\hline $\begin{array}{l}\text { I found the feedback and comments from } \\
\text { peers or different groups on learning } \\
\text { activities informative. }\end{array}$ & & & .568 & \\
\hline $\begin{array}{l}\text { The self-reflection activity in 3D-STS was } \\
\text { useful for learning. }\end{array}$ & & & .638 & \\
\hline $\begin{array}{l}\text { The activities in 3D-STS helped me to } \\
\text { articulate my thoughts clearly. }\end{array}$ & & & & .419 \\
\hline $\begin{array}{l}\text { The learning approach built into 3D-STS } \\
\text { was new and attractive. }\end{array}$ & & & & .729 \\
\hline I am satisfied with 3D-STS. & & & & .815 \\
\hline Mean & 4.45 & 4.20 & 4.11 & 4.37 \\
\hline Eigenvalues & 3.701 & 2.528 & 2.512 & 2.328 \\
\hline$\%$ of Variance & 28.301 & 14.265 & 11.758 & 9.517 \\
\hline Cumulative variance & 28.301 & 42.566 & 54.324 & 63.841 \\
\hline Cronbach's $\alpha$ & .807 & .762 & .757 & .712 \\
\hline
\end{tabular}

Further, multiple regression analysis was performed to investigate the relationship of overall satisfaction with respect to interface and situation, tools and function, and communication mechanism. In Table $4, \mathrm{R}^{2}$ $=0.518, \mathrm{~F}=127.548, \mathrm{p}<0.001$, the relationship was shown to be significant. The interference of 3 dimensions (interface and situation, tools and function, and communication mechanism) could explain $51.8 \%$ variance of overall satisfaction. The independent $\beta$ values for interface and situation, tools and function, and communication mechanism were $.138(\mathrm{t}=2.828, \mathrm{p}<0.05), .251(\mathrm{t}=3.648, \mathrm{p}<0.001)$, and $.314(t=5.783, p<0.001)$, respectively. The result was shown to be significant. These findings indicate a positive relationship among overall satisfaction, interface and situation, tools and function, and communication mechanism. 
Table 4 Summary of Multiple Regression Analysis

\begin{tabular}{llcc}
\hline Dependent variable & Independent variable & $\beta$ & $\mathrm{t}$ value \\
\hline \multirow{2}{*}{ Overall satisfaction } & Interface and situation & .138 & $2.828^{*}$ \\
& Tools and function & .251 & $3.648^{* * *}$ \\
& Communication mechanism & .314 & $5.783^{* * *}$ \\
\hline $\mathrm{F}=127.548^{* * *}, \mathrm{R}^{2}=.518$ & & \\
\hline$* \mathrm{p}<.05, * * \mathrm{p}<.01, * * * \mathrm{p}<.001$ & &
\end{tabular}

The data obtained from the interviews of the 20 trainees showed that the majority of them (18 out of 20) thought that 3D-STS was a unique and novel experience. They reported that 3D-STS was more interesting than traditional training courses because of the animation and interactions. Some said that 3D-STS was attractive enough to keep them motivated during the course. The online discussion made trainees feel more involved in the learning activities. Eight trainees suggested that the participation of senior tour guides in the online discussions would have been helpful because they sometimes did not know how to solve problems without the scaffolding provided by the latter. The trainees made statements in the interviews such as 'I would learn better if the senior tour guide was involved in the online discussion', 'The feedback from the senior tour guide was useful and practical in helping me solve my problems', and 'If the senior tour guide could participate in the online discussion, it would increase the interactions and clear up confusion'.

The trainees also pointed out that reflecting on their experiences in their journals promoted the articulation of their thoughts, though a few stated that they needed instructors' assistance because they lacked communication and reflective thinking skills. These findings are in keeping with Caudron's (2001) observation that the quality of online learning classes varies considerably owing to instructors who fail to provide timely and consistent feedback to the learners.

Computer logs showed that fewer male trainees than female trainees participated in the online discussion. More than half of the male trainees said in interviews that the animations in 3D-STS, especially playing as an Avatar, were as attractive as online games, reporting that they paid more attention to playing as an Avatar and less to the learning materials. All of the male trainees said that they were not used to performing self-reflection tasks online, making statements such as 'I don't like to engage in introspection online' or 'I would rather do self-reflection by myself than online'. Their interest in the entertainment aspects of the course and their resistance to reflective activity may have reduced male trainees' desire to construct their knowledge using 3D-STS. In contrast, however, one female interviewee said, 'I like the activity of self-reflection online. Being able to reflect on my experience in my journals promoted the articulation of my thoughts'. Interestingly, the majority of trainees mentioned that working together with peer trainees contributed to making their learning meaningful.

\section{Conclusions: Implications, limitations, and new directions}

This study investigated the effects of a 3D-STS program developed to cultivate situated learning for tour guides in training. In this study, a realistic computer-simulated situation served as a bridge to connect trainees' daily-life experiences and help them construct relevant knowledge. At the same time, networked technologies supported collaborative work in which the trainees combined components in order to achieve successive learning (Wiske, 2000). To achieve effective cooperation, trainees had to share ideas and debate with others so that they could come to reasonable interpretations of the subjects they were studying. Trainees were thereby able to compare varied views on a topic and obtain a cohesive understanding of tour guide-related knowledge through a well-designed online discussion. 3D-STS also succeeded in helping trainees to integrate knowledge, stimulating discussions in response to questions that probed realistic situations. As Yamagishi et al. (2012) note, meaningful learning occurs when trainees 
interact with others or with environments; when trainees communicate with others, they receive pre-knowledge and reconstruct concepts. Similarly, Gask, Goldberg, Lesser \& Millar (1998) found that trainees instructed in problem-based models and taught in a group setting significantly improve in terms of performance. Therefore, the first implication for educators is that online asynchronous and synchronous discussions designed for a situated learning environment with 3D-STS can promote knowledge integration.

In both the questionnaire surveys and the interviews, most trainees viewed 3D-STS positively. This may be because computer-mediated training is self-paced and trainees are given various opportunities to explore relevant and interesting material. Some interviewees said that the animations for the simulated authentic situations increased their learning motivation and immersed them in an interesting context for meaningful learning. However, the interviews also suggest another implication for practitioners/educators, namely, that well-trained instructors be involved in online communication with trainees in order to help less-experienced trainees overcome their obstacles when using IT.

In terms of gender differences, all of the male interview participants reported that they were not used to performing self-reflection tasks online. This result differs slightly from earlier studies by Houta and Gupta (2001) and Shashaani and Khalili (2001), who found that females exhibited lower confidence than males in their ability to use IT. One possible explanation for our results could be cultural conventions; some have reported that Asian males do not like to engage in open self-reflection (Yamagishi et al., 2012). The scores on all four dimensions of the 3D-STS are higher than 4.00, indicating that the trainees were satisfied with 3D-STS. However, the dimension of communication mechanism ranks last among the four dimensions, which suggests that more efforts are needed to determine how best to meet trainees' communicative needs and how to systematically incorporate such methods into the 3D-STS. A good training program will affirm high performance standards while creating friendly, dynamic, and situated learning environments.

Certain limitations of the study must be acknowledged. This study drew on multiple advanced technologies, such as Second Life's 3D, online, and Avatar features, which were fully integrated in the training courses. Insufficient familiarity with the tools could be a major obstacle for some users, interfering with their ability to access and process e-learning content. It is also important to note that this study was preliminary and exploratory in nature. The analysis consists entirely of self-reported data and thus depends on participants' honesty in describing their perceptions of 3D-STS. A further limitation of this study was that it provided only a 'snapshot' of a fairly brief moment in time; its scope is not a diachronic one. It must also be recognized that the participants were new tour guides with at most six months of experience, and they volunteered to participate in this study. Clearly, this was a self-selected group whose expectations may have differed from those of a more representative sample of tour guides. As in any case study, therefore, we urge caution in generalizing any findings to larger populations.

One of the most robust findings in this study was the surprising gender difference in 3D-STS playing. Moghaddam (2010) proposed that in addition to gender, culture is also an important factor in the adoption of information and communication technology among different nations. The term 'gender' refers to different roles men and women play in a society or a community. Jackson et al. (2010) also indicated that men and women are socially constructed for different tasks, and this may influence their pattern of IT usage. The findings reported here suggest a need for future research that addresses other social parameters in IT use, such as differences in culture, socioeconomic status, age, or ethnicity. These parameters may also intersect in complex relations, and we stand to gain much from exploring them in greater detail.

Learning occurs naturally while playing games (Li \& Tsai, 2013). As Gee (2007) noted, 'you cannot play a game if you cannot learn it' (p. 3). For more effective training outcomes for tour guides, tourism educators should be aware of the dynamic nature and the rich possibilities of 3D-STS, whose advanced technologies can be used to design interesting learning opportunities and expand and deepen participants' experience. Findings from studies like this one can assist tourism practitioners and educators in developing effective training programs, enhancing relative competitiveness, and maximizing learning outcomes in employee training. 


\section{References}

Blanke, J., \& Chiesa, T. (2008). The travel and tourism competitiveness index: Measuring key elements driving the sector's development. In J. Blanke \& T. Chieas (Eds.), The travel \& tourism competiveness report 2008: Balancing economic development and environmental sustainability (pp. 3-26). Geneva, Switzerland: World Economic Forum (WEF).

Bonk, C. J. (2002). Online training in an online world. Retrieved October 15, 2012, from http://www.PublicationShare.com

Broadribb, S., \& Carter, C. (2009). Using second life in human resource development. British Journal of Educational Technology, 40(3), 547-550.

Brohman, J. (1996). New directions in tourism for third world development. Annals of Tourism Research, 23(1), 48-70.

Broos, A. (2005). Gender and information and communication technologies (IT) anxiety: Male self assurance and female hesitation. Cyber Psychology \& Behavior, 8(1), 21-31.

Caudron, S. (2001). Evaluating e-degrees. Workforce, 80(2), 44-47.

Cockburn, A., \& McKenzie, B. (2002). Evaluating the effectiveness of spatial memory in 2D and 3D physical and virtual environments. CHI '02 Proceedings of the SIGCHI conference on human factors in computing systems: Changing our world, changing ourselves. New York: ACM.

Dede, C. (2009). Immersive interfaces for engagement and learning. Science Magazine, 323(5910), 66-69.

Downing, R. E., Moore, J. L., \& Brown, S. W. (2005). The effects and interaction of spatial visualization and domain expertise on information seeking. Computers in Human Behavior, 21(2), 195-209.

Eilat, Y., \& Einav, L. (2004). Determinants of international tourism: A three-dimensional panel data analysis. Applied Economics, 36(12), 1315-1327.

Falloon, G. (2010). Using avatars and virtual environments in learning: What do they have to offer? British Journal of Educational Technology, 41(1), 108-122.

Gask, L., Goldberg, D., Lesser, A. L., \& Millar, T. (1998). Improving the psychiatric skills of the general practice trainee: An evaluation of group training course. Medical Education, 22(2), 132-138.

Gee, J. P. (2007). What video games have to teach us about learning and literacy (2nd ed.). New York: Palgrave Macmillan.

Hall, C. M. (2006). Introduction to tourism in Australia: Development, issues and change. Australia: Pearson Education.

Herrington, J., \& Oliver, R. (2000). An instructional design framework for authentic learning environments. Educational Technology Research and Development, 48(3), 23-48.

Houta, L. E., \& Gupta, U. G. (2001). Nebraska high school students' computer skills and attitudes. Journal of Research on Computing in Education, 33(3), 316-326.

Jackson, L. A., Eye, A., Fitzgerald, H. E., Zhao, Y., \& Witt, E. A. (2010). Self-concept, self-esteem, gender, race and information technology use. Computers in Human Behavior, 26, 323-328.

Jones, J. G., Morales, C., \& Knezek, G. A. (2005). 3-Dimensional online learning environments: Examining attitudes toward information technology between students in Internet-based 3-dimensional and face-to-face classroom instruction. Educational Media International, 42(3), 219-236. 
Lau, R. W. H., Yen, N. Y., Li, F., \& Wah, B. (2013). Recent development in multimedia e-learning technologies. World Wide Web, doi: 10.1007/s11280-013-0206-8

Lee, J. H., Lee, S. H., \& Kim, J. W. (2004). Design principles of online environments for Chinese language learning. Multimedia-Assisted Language Learning, 7(2), 315-333.

Lee, S. H., Kim, J. W., Lee, J. H., \& Liu, X. (2005). The effectiveness of online situated environments for language learning. 21st Annual Conference on Distance Teaching and Learning. Retrieved from http://www.uwex.edu/disted/conference

Li, M. C., \& Tsai, C. C. (2013). Game-based learning in science education: A review of relevant research. Journal of Science Education Technology, 1-22. doi: 10.1007/s10956-013-9436-x

Margolis, J., \& Fisher, A. (2002). Unlocking the clubhouse: Women in computing. Cambridge, MA: The MIT Press.

McLellan, H. (1996). Situated learning: Multiple perspectives. In H. McLellan (Ed.), Situated Learning Perspectives (pp. 5-15). Englewood Cliffs, N.J.: Educational Technology Publications.

Mitra, A., Lensmeier, S., Steffenmeier, T., Avon, R., Ou, N., \& Hazen, M. (2000). Gender and computer use in an academic institution: Report from a longitudinal study. Journal of Educational Computing Research, 23(1), 67-84.

MOEA (2009). The status of Taiwan's tourism \& recreation industry. Department of Investment Services, Ministry of Economic Affairs. (June 2009). Government Information Office, Republic of China (Taiwan).

Moghaddam, G. G. (2010). Information technology and gender gap: Toward a global view. The Electronic Library, 28(5), 722-733.

Muirhead, B., \& Betz, M. (2002). Faculty training at an online university. USDLA Journal, 16(1). Retrieved September 28, 2012, from http://www.itdl.org/DistEdReader.pdf\#page=107

Qian, Y. (2008). Learning in 3-D virtual worlds: Rethinking media literacy. Educational Technology, $48(2), 38-41$.

Omale, N., Hung, W. C., Luetkehans, L., \& Cooke-Plagwitz, J. (2009). Learning in 3-D multiuser virtual environments: Exploring the use of unique 3-D attributes for online problem-based learning. British Journal of Educational Technology, 40(3), 480-495.

Shashaani, L., \& Khalili, A. (2001). Gender and computers: Similarities and differences in Iranian college students' attitudes toward computers. Computers \& Education, 37(3-4), 41-51.

Smith, R. M. (2008). Conquering the content: A step-by-step guide to online course design. San Francisco, CA: Jossey-Bass.

Stevens, J. (2002). Applied multivariate statistics for the social sciences (4th ed.). Hillsdale, NJ: Lawrence Erlbaum.

Wiske, S. (2000). A new culture of teaching for the 21 st century. In D. T. Gordon (Ed.), The Digital Classroom (pp. 45-68). Cambridge, MA: The Harvard Education Letter.

Wong, S. L., \& Hanafi, A. (2007). Gender differences in attitudes towards information technology among Malaysia student teachers: A case study at University Putra Malaysia. Educational Technology \& Society, 10(2), 158-169. 
Yamagishi, T., Hashimoto, H., Cook, K. S., Kiyonari, T., Shinada, M., Mifune, Inukai, K., Takagishi, H., Horita, Y., \& Li, Y. (2012). Modesty in self-presentation: A comparison between the USA and Japan. Asian Journal of Social Psychology, 15, 60-68.

Zielinski, D. (2000). Can you keep learners online? Training, 37(3), 64-75.

Corresponding author: Yu-Fen Chen, bephd@mail.chihlee.edu.tw

Australasian Journal of Educational Technology (c) 2014.

Please cite as: Chen, Y. \& Mo, H. (2014). Users' perspectives on tour-guide training courses using 3D tourist sites. Australasian Journal of Educational Technology, 30(1), 80-91. 